\title{
Research and Reflection on Folk Art in Innovative Practice Teaching of Animation
}

\author{
Taking Shadow Art as an Example*
}

\author{
Zhuo Ding \\ Art Education Center \\ School of Automation \\ Northwestern Polytechnical University \\ Xi'an, China 710072
}

\begin{abstract}
China's shadow art has a long history and a profound cultural heritage. This paper focuses on the new trend of college animation education from the perspective of folk art. From the perspective of the combination of traditional art and digital design, this paper discusses the exploratory teaching model of the interaction between folk art and teaching, as well as the interaction and integration between animation and regional folk art. At the same time, it puts forward the new ideas of cultivate mode of animation and innovative talents in colleges and universities.
\end{abstract}

Keywords—shadow painting; animation; practice teaching

\section{INTRODUCTION}

The report of the Ninth National Congress of the Communist Party of China put forward "to promote the creative transformation and innovative development of the Chinese traditional culture." It is of great importance to strengthen traditional national culture. Chinese shadow art comes from the life, it reflects the wisdom of our national working people and a good yearning for life. Shadow art is the wisdom and precious heritage of the Chinese nation. In recent years, with the strengthening of globalization and the rapid development of modern information technology, the intangible cultural heritage has been under great pressure and shock, some cultural heritage that relies on dictation and behavior is endangered. At the same time as the community pays more and more attention to China's animation market, the needing of related talents is also rapidly expanding. However, at present China is seriously lacking of animation talents, scarcity of high and the end of talents has become the bottleneck of its development resulting in the phenomenon that animation industry talent is difficult to find. How to use and inherit regional folk art, and promote the Advanced Research and Curriculum Innovation of Folk Art in College Animation, as well as cultivate animation and innovative talents, is an important part of college animation teaching research. Establishing teaching model "take research learning as the center, take folk art as the theme, combine classroom teaching and social practice", and carrying out the teaching of folk art not only can inherit and carry forward the

*CLC number: J218.7 - Document code: A national culture giving rise to the fact that students are influenced by folk art, but also can better cultivate students' aesthetic ability and innovation consciousness.

\section{THE CURRENT SituATION OF RESEARCH AT HOME AND ABROAD}

At present, the study not only is concerned about the history of shadow play, production methods, singing, stage effects, but also mostly analyzing and comparing the Artistic Features of the Geography Schools from the artistic point of view, adding to picture information for appreciation of the introduction. In the postgraduate art teaching and research, although a lot choose the folk art of shadow art as a topic or theoretical research, the study of the traditional shadow art mostly stays in the inheritance, protection and research, lacking of using modern digital technology for the development of traditional art to achieve the traditional art of revitalization of the industrialization model. And the out of line between art education and art practice, scientific research is very serious. From the research field, the domestic study of folk art can be said to be the most extensive, most in-depth, and all kinds of monograph and paper of research shadow art are the most. From the current research trend, in addition to strengthening in-depth excavation of the cultural value of folk art, the main problem is how to inherit the shadow, how to develop, how to adapt to the new era. Therefore, the future research trend may be more focused on the development of digital media and shadow art innovation applications.

From the perspective of the combination of traditional art and digital design, the win-win model of traditional shadow art and digital design development is explored and studied by means of the cultural of traditional shadow art and original creativity of the artistic design. This is not only the basic subject of the development of cultural and creative industries in our country, but also the reality of traditional process protection and development in the process of modernization. At the same time, it is still a professional subject which cannot be avoided in the teaching and research of art design and related design in higher education. From the design of originality, the essence of our rich traditional arts and culture 
is absorbed to put the original design of the important cultural resources to be used. Using the digital and multimedia information technology to integrate, machine, process and research the traditional shadow art and cultural resources, so as to establish suitable teaching and research for college art design and related design majors and promote the win-win development of shadow art and new media.

At present, China's animation talent is in shortage, scarce talent can be divided into the following six categories: the original story talent, animation software development talent, three-dimensional animation production talent, animation product design talent, game development talent and animation game marketing talent. And now engaged in animation creation line is the vast majority of a single type of technical personnel, complex type of creative talent is very few. In the national "thirteen five" planning policy, many colleges and universities and training institutions are mostly focused on the late technical production personnel training, and training of talent can only be limited to the "processing" of the technical positions, it is difficult to cultivate a truly innovative Cartoon talent. As a result, the predicament of "hard to find" emerges, which can be expressed that the major animation company paying the tens of thousands of monthly salary to find a talent is hard.

Analysis of the status of the lack of talent for the animation industry quo: 1, animation talent training structural imbalance. Top-level original staff such as screenwriter, director, production is extremely lacking. 2, the overall quality of China's cartoon talent is not high. Animation talent lack the influence of traditional culture. China's animation industry is currently lack of Chinese cultural traditions, regional characteristics and deep and lasting attraction. Animation product selection is too limited, with a strong preaching color, lack of flavor of the times.

\section{A. Research Strategy}

Under the background of the humanities quality education curriculum in colleges and universities, the comprehensive practice is very important. The teaching of the shadow play can not only inherit and carry forward the national culture, but also has important positive significance for the construction of the campus culture. The ability to cultivate innovative talents and their innovative ability generally has the following characteristics: the ability of independent thinking and the spirit of forging ahead, the habits of multidimensional thinking, the ability to think about each other, the ability to summarize and the ability to seek the inherent laws of the development of things [2]. In order to make the folk art of the characteristic teaching more in-depth development, become the school's characteristics, brand, and for the promotion of national culture to do a responsibility, we must look forward to the concept of guidance for the teaching practice. Take the folk art of shadow art as the basis, cultivate a regional cartoon talent for the study of the folk art of shadow art, develop and utilize folk shadow art resources, extend the classroom to the folk art to learn the essence of art, play the advantages of folk art resources, cultivate original creative talents, establish the new concept of animation art education, seeking for sustainable development of cultivating innovative talents for China's animation industry.

\section{B. Exploratory Teaching}

In the past teaching, often with skills as the focus of teaching, training-based teaching and spoon-fed teaching are implemented. This kind of teaching method which only focuses on the teaching of knowledge and ignores the student's main learning does not take into account the inherent needs of the students, it is difficult to stimulate the students' curiosity, nor can they provide students with the necessary environment for innovation and the opportunities of innovation and practice, suppressing the student initiative and creative development to a large degree [2,3,5]. But exploratory teaching is different from the training-based teaching, focusing on starting from the inquiry. In the course of teaching, under the guidance of teachers, students can use the "self, exploration, cooperation" as the characteristics of the learning style to make study shadow language, shadow in the sound, shadow figure modeling, stage design, character and action performance and other major be carried out in self-learning, in-depth study and group cooperation and exchange. Through the study of national style and national culture in the art of shadow play, students are cultivated to get a deeper understanding of the nationalization of art.

In the actual teaching, you can set the appropriate teaching links to help students' better grasp the relevant knowledge.

1) Situational teaching: According to the progress of teaching, after teachers determining the knowledge point, the teaching starts around this point of knowledge. Through the problems, tasks and other forms, teachers use appropriate teaching methods to create learning objects associated with this learning situation, and guide students to enter the learning of target knowledge point. For example, in the knowledge of how the domestic animation learn from the form of elements of the shadow art, you can guide students in-depth study in the form of asking questions. Through the arrangement of tasks, to guide students to analyze domestic animation works, to find a universal and representative aesthetic style features, while with horizontal comparison, to analyze traditional aesthetic characteristics of domestic animation. And then from the form of expression of the shadow art, to explore the means of reference between the domestic animation and shadow art expression.

2) Inspired thinking teaching: After the knowledge points determined, in order to make the inquiry-based teaching effective, it is necessary to make a number of questions before the inquiry, which can cause the students to think deeply and are closely related to the current learning object so that the students can take these questions to explore. In order to make students better finish the study of domestic animation how to learn from the knowledge of the form of the shadow art, this paper puts forward how the local atmosphere of the shadow art and the national 
animation fit, how to learn from character modeling and acting form of the shadow art. Students explore these inspiring and reflective questions of the influence of shadow art on the form and style of domestic animation. This link is crucial, whether the question raised is instructive, whether it can cause students to think deeply, which is the key to whether the inquiry study can achieve the effect or even the success or failure.

3) Explore in groups: In the way of learning of "autonomy, exploration, cooperation", the group cooperative learning activities are implemented. Students 'innovative spirit stems from their strong interest in exploring unknowns. Innovative education begins with the awareness of students' problems and actively encourages students to ask questions. This requires the reform of the traditional single indoctrination of teaching methods, changes the previous "teach what" as "how to teach", and makes more use of interactive teaching forms. In classroom teaching, teachers should be changed from coaches to coparticipants, respect for the student's dominant position, encourage students to participate in classroom discussions, boldly question, and then develop their initiative to find problems and solve problems. [1] Teachers play a guiding and supportive role, students should give full play to the initiative and enthusiasm of learning, information technology should become a cognitive tool for student inquiry. By allowing students to surf the Internet to find information to achieve the purpose of promoting students to explore by themselves, these data can play the role of cognitive tools. This link is the key teaching link.

4) Cooperation and communication: This link is closely linked with the independent inquiry link. Cultivate students' innovative ability. In the process of education and teaching, teachers should use various opportunities to guide students to participate in practice, promptly encourage them to boldly express their new ideas, take the initiative to communicate with the surrounding students, explore, and actively take the opportunity of a variety of experiments, internships and social practice, guide students to consciously, positively perform, test their own new ideas. [1] Teachers should organize, coordinate, and guide students to design animation topics from the nationalization of folk art. After a serious self-exploration of national elements of the art of shadow, and actively think about these issues of how the shadow art and the development of modern animation nationalization combine, the students enter the high-quality collaborative communication stage. Collaborative communication must be based on the self-exploration, so as to provide students with the platform of ideas communicating, ideas, collision, sharing.

5) Summary to improve: Teachers guide students to answer and summarize the problems of the nationalization of animation, analyze the study results, and can be linked to the actual, put the creative writing of the current shadow art integrating into the animation into deepening, promotion and second creation, so that it can be adapted to the animation teaching needs, as well as focus on developing students' thinking and vision.

\section{FIELD RESEARCH}

Carry out the field study of the artistic characteristics of the shadow and the form of performance, students make use of field research activities to collect research information, and put the enormous collected data to sort, analysis, synthesis, comparison and induction.

The gradual transition from simple teaching to the development of shadow products design planning

Explore the development path of inheritance and development of shadow art under the influence of new media. And study how to combine the ideas of modern digital design with the traditional shadow art and how to apply it. Explore the symbolic culture of finishing the shadow art image, and explore the feasibility and realistic way of high value-added of designing cultural products. This paper explores the expanding of digital technology to the application of shadow animation film, how to apply the modeling and expression of shadow art to the design of domestic animation.

\section{A. Practical Results}

The combination of folk art and art education in colleges and universities not only opens up the educational model of pluralistic art in colleges and universities, but also inherits, promotes and develops folk art. The establishment of animation industry brand innovation strategy of regional folk art resources development which is based on regional folk art resources sees the protection and development of regional folk art resources as the revitalization of the animation industry's priority. It enhances the national cartoon industry's core competitiveness through the regional folk art resources in-depth development and excavation. Let's create a win-win situation of training creative talents of college animation training and heritage and development of folk art. When applying Shadow Art to the national animation teaching activities, it cannot only enhance the students' awareness of protecting the folk culture, but also enrich the content of folk culture and art database. Over the past few years, I'm concentrate on committing to the construction of folk culture and art database in order to protect the precious and even endangered folk art. Students' accomplishment and acknowledge has been greatly improved through the study of folk art which can not only enrich the content of animation research practice activities, but also provide a design creation platform for graduate students, students can carry out folk art research activities in better performance through this research platform.

\section{B. Thinking about How to Deal with the Problems of Tradition and Modernity, Inheritance and Development}

There are many advantages for animation learning from the traditional Shadow shape images. Animation is the combination of literature, painting, music, performance, photography and other artistic means which has their own 
unique narrative language and manifestations. In the development process of The Shadow, it absorbs of the essence of other art, forming a unique style of modeling and performance forms. It is important to deal with the problem that how to make full use of resources of the Shadow and make it suitable for the development of Animation creation to revitalize the Chinese national animation industry.

From the perspective of animation teaching, we explore the way of development of shadow art and the animation nationalization starting from the study of Shadow art. We use Modern Science and Technology to reinterpret Traditional Shadow Forms. We dig up the traditional cultural spirit and artistic style presented by Shadow Art from the content and form with the help of the form of Shadow Art and form of expression. We can apply some typical elements of Shadow Art, including modelling, performance, stage styling and music, to the theoretical research and actual creation of animation. We can see how the shadow form elements used in animation design creation by traditional cartoon named <Judgment by Zhang Fei>. There are a large number of shadow form elements in the cartoon named $<$ Judgment by Zhang Fei>.From the overall shape of the cartoon style, the figure is two-dimensional plane modeling. It is a unified plane composition to any person or object. There are all side lens to the head, face and body of the figure. There are seldom positive facial features. The objects are not like to three-dimensional objects because they are almost same looks from any direction. The soma, limbs and clothing of figure are also shown a significant flat. There are no front-and-back differences between two figure or objects and scenery objects. There are only left-and-right differences between them. It perfectly shows the flat style and rich decoration of Shadow Art on the screen. The shadow styling of Zhang Fei has a frown face, a nose like lion's and eyes like leopard's, and exaggerated and deformed mouth. The outline of Zhang Fei is rough and unrestrained, with the radial lines to reflect the rampaged irritability and courage of this character. This is particularly similar to the character in the animation, who has big round eyes, thick black beard, wearing armor. The characters of local council junior officers in animation are very similar to the antic characters in the Shadow Art who have big round eyes, high eyebrows, big noses, and buffoonery. The peasant women in animation are also almost same to the persons in Shadow Art who have bent brow, line-liked eyes, knife-liked nose and red lips.

In the scene design, the scenery of "Judgment by Zhang Fei" is similar to the shadow, which have expressed as the large surface, bright background dark prospects, like the shadow screen of shadow. The main body set off particularly prominent, full and full composition, decorative means strong, clever layout. In the use of color and the color method of shadow is similar. Based on red, yellow, green, black and white to boldly use of complementary color, to make a strong contrast to the big red and the big green, and to chunk line chisel white, natural reconcile. In the animated cartoon, Zhang Fei's image by the red, yellow, black with three colors, and the land by the black and blue, showing the stupid character of the role. In the action design, the figure in "Judgment by Zhang Fei " have longer upper body and arms, an arm is divided into three sections, upper arm, arm and hand; the mechanical action design as if behind someone in control it is very similar to the movement motion of shadow character. It is easy to see that the previous domestic animation in the shape, color, scene layout and movement, are more or less borrowed from the form elements of the shadow art. As the animation designers of the new generation, should pay attention to look at the most expressive modeling language in the Chinese native art. [4] (29-31) Guide students to materialize, personalize these rich images and to be refined in the teaching activities.

While inheriting, we should pay attention to the integration of tradition and modern, and find animation language from the local culture. The essence of this nation's culture is embodied in the ideas and content to reflect the aesthetic and spiritual needs of modern people. In the form of art, the national elements of traditional shadow art are borrowed and the local cultural spirit is integrated into the animation to create the national animation with modern characteristics. Learn from the art form of traditional shadow to find the interconnection between the tradition and modern. It can not only enrich the expression means of national animation, but also can promote the development of national animation creation, at the same time also play an important role in inheriting and developing the folk shadow art. Taking "Peach Blossom Spring" as an example to explore the new development of animation creation.

The various artistic features of Shadow art in "Peach Blossom Spring" was shown most incisively and vividly. The character modeling with the manifestations of shadow modeling and shadow modeling are the same as twodimensional plane modeling. All the characters are shaped like a shadow figure modeling, that is the animation plane features that the head portraits in animation are the side, with the side face to show the story. The shadow modeling has a strong artistic exaggeration and artistic induction characteristics.

In the "Peach Blossom Spring" cartoon, the character modeling is designed by the abstract and realistic combination, the character attire and face charm vivid image, exaggerated humor, humorous and romantic. Adopting the line hollowing method with shadow-carved to depict the specific image. In the use of color on the concise, flat painted color. The character modeling is carried out extremely bold art exaggeration and induction in the process of animation creation, the image features with simple lines and hollow characteristics are carried out most vividly.

In the characterization of the characters, the characteristics of cartoon image are absorbed, the face image is exaggerated, vivid and fresh and beautiful, reflecting a variety of different personality and class identity, with a very concise way to describe the loyalty and evil characters in the story, and with its distinctive color to reflect the emotion of love and hate.

In the "Peach Blossom Spring", the shape of the image is linked with the traditional opera, and character modeling has a strong form of opera. Especially in the character modeling performance, that boldly into the absorption of facial and 
opera costumes of the essence of art. The characterization of the characters in the animation is simpler than the performance of the comedy, and the image is more general and more vivid. The image of the clown in the cartoon shows an insidious cunning image of the ugly in the hawk-nosed and vulture-eyed to portray the character. The feather wings on both sides of the official hat are treated as the back of the head. The front collar is also treated as a side, but symmetrical bun is treated as a half. This is all based on the shadow itself and the author's aesthetic requirements for flexible treatment, but not subject to the real life image and focus of the law of the restrictions and constraints. "Peach Blossom Spring" also borrowed the traditional Chinese painting, paper-cut the traditional art of expression in the means of expression. This is different from the traditional shadow art with the traditional Chinese painting techniques to create a brilliant and level of space strong sense of the scene, as well as the traditional shadow modeling innovation. The cartoon shows the perfect mood of Chinese culture through the perfect fusion of using computer digital technology and traditional Chinese artistic expression techniques. Not only in the new areas of animation innovation to expand, but also allow Chinese traditional art to be more favorable protection and development through the modern cultural media.

With the continuous improvement of digital technology, we can try to film the concept of time, tone concept, montage techniques and sub-lens design combined into the shadow animation, rich shadow animation language. We can try to make the film's concept of time, sound and picture concept, montage techniques and sub-lens design combined into the shadow animation to rich shadow animation language through the intervention of digital technology. Using digital technology, to make innovative production for the creation of shadow animation, which is also conducive to its creation, packaging and dissemination of the redevelopment.

Through integrate the research on the Art of Folk Shadow into the animation innovation creative teaching activities, which not only breaks through the talent training mode of copying the foreign animation specialty in the past in the innovative concept of animation talent training, but also make the positioning of talent training is more accurate, showing regional, applied and innovative. Through integrate Shadow Art into the animation innovation creative teaching activities, which is conducive to the excavation, collation and reproduction of folk art to arouse students' memory of folk art and broaden their horizons. It will make them become the inheritors and disseminators of the national culture and art, which could service for the construction of the harmonious society and make new contributions to building a harmonious society for the national culture and arts heritage, promotion and development. From the perspective of folk art to study the new trend of animation education of Colleges and universities, animation and regional folk art interaction and integration and other issues.

\section{CONCLUSION}

Combined with the interactive teaching mode of folk art and teaching interaction, the teaching form in the innovative teaching of animation into the folk art of the traditional art elements provide a new entry point for the universities of the approach of animation talent training. And it provides ideas for the college animation creative talents training mode, which could enrich the connotation of traditional culture and education and also improve the quality of animation talent training. At the same time linked the animation talent training with animation industry development. It will not only enhance the artistic quality that the cartoon talent should have, but also promote the development of animation industry economy better. From a more extensive sense, it can make a new contribution to the inheritance, promotion and development of national culture and art.

\section{ACKNOWLEDGEMENT}

This research was supported by the Social Science Foundation in Shaanxi Province in 2014(2014I13) and the "13th Five-Year" Education Science Planning Project in Shaanxi Province in 2017 (SGH17H043) and 2015 Shaanxi art subject (2015SY065) and the Central University funding projects.

\section{REFERENCES}

[1] Qin Jun, Wang Aifang. Research on the training mode of innovative talents in Colleges and universities in China [J]. teaching research, 2009, (4), 13-17.

[2] Zhang Xinyun, Nan Guo Jun. Reflections on the cultivation of innovative talents in Colleges and universities [J]. Liaoning: Journal of Engineering Technology University (SOCIAL SCIENCE EDITION), 2005, (3): 221 - 222.

[3] Zheng Jiamao, pan Xiao Hui. Innovative education in universities calls for a breakthrough in the reform of personnel training mode [J]. Jiangsu higher education, 2008, (1):83-85.

[4] Luo Yong Jian. Shadow art and the form of nationalization development of domestic animation [D].Northwestern Polytechnical University, 2008,28-31,35-37.

[5] Zhao Huan. On the construction of teaching mode of innovative talents in Universities [J]. Heilongjiang Education (higher education research and assessment Edition), 2006, (11):42-44. 